\title{
Study of Different Therapeutic Agents for the Prevention of Ischemia Reperfusion Injury in Free Skin Flap
}

\author{
KHALED EL-GAZZAR, M.D.*; IBRAHIM HUSSEIN KAMEL, M.D.; EMAN NAGY, M.D.; \\ EMAN ABDEL-SALAM IBRAHIM, M.D.**; MAI MOSAD MORSY, M.Sc. and AHMAD ALI HASSAN, M.D.
}

The Departments of Plastic Surgery* and Pathology**, Faculty of Medicine, Ain Shams University

\begin{abstract}
Background: In clinical practice a certain fraction of skin flap transfers fail invariably because of ischemia-reperfusion injury. This study was designed to develop experimental model of ischemia-reperfusion injury in rat skin flap to investigate the effect of certain pharmacological agents on prevention or reducing ischemia-reperfusion injury.

Methods: A " $4 \times 6$ " $\mathrm{cm}$ hemi epigastric skin flap of adult albino rat was raised and subjected to 8 hours of ischemia then reperfusion for 48 hours. A total of 40 flaps were studied and divided randomly into 5 groups. 15 minutes prior to reperfusion, all flaps (except group I) were infused by saline, Vitamin C, Heparin, and Monoclonal antibody LY-6G to groups II, III, IV and V respectively. After 2 days, macroscopic evaluation of flap survival, histological study of neutrophil infiltration, and biochemical tissue enzymes assay were performed.
\end{abstract}

Results: All flaps survived completely in sham group I with minimal neutrophilia while the mean percentage of flap necrosis in control group II was $90.5 \%$ with massive neutrophilia. The mean percentage of flap survival were 71,80 , and 84 percent in groups III, IV, and V respectively. Neutrophil count of flap tissue showed significant reduction as compared with control flaps. Tissue enzymes assay showed stable level of superoxide dismutase activity in flaps pretreated by drugs compared to control group. Caspase- 3 enzyme activity showed variable decrements in flaps pretreated with the different drugs when compared with control flaps.

Conclusion: The use of certain pharmacological agents could significantly reduce the effect of ischemia-reperfusion injury on skin flaps.

Key Words: Ischemia-reperfusion - Vitamin C - Heparin Monoclonal antibody.

\section{INTRODUCTION}

Ischemia-reperfusion (I/R) injury occurs when tissue is re-perfused following a variable period of ischemia [1,2]. It is one of the leading causes of flap necrosis that represents a subject of interest to plastic surgeons involved in replantation and free-tissue transfer. Failure rates of microvascular tissue transfer have been reduced significantly because of the improved technique, patient selection, and proper flap design resulting in the increased spectrum of tissue reconstruction [3-5]. Despite these successful developments, flap failure remains a costly and psychological upset. Beside technical mistakes leading to compromised arterial blood supply or venous drainage, several metabolic events occurring during and after tissue transfer seem to account for considerable rates of flap loss. It has been emphasized that I/R injury plays a crucial role among these devastating pathologic mechanisms leading to the no-reflow phenomenon within microcirculation [6-7].

Since I/R injury is a multifactorial pathology, several techniques and pharmacological agents were studied and tried to improve the survival of free flap transfer [8-15]. Free oxygen radical scavenger in the form of vitamin $\mathrm{C}$ (ascorbic acid) is an endogenous water-soluble compound that is virtually non-toxic and capable of reducing free oxygen radicals. The reported therapeutic effects of this vitamin may be due to its antioxidant activity on various free radicals $[\mathbf{1 2 , 1 6 , 1 7 ]}$. Vitamin $C$ is known to block lipid peroxidation in the cell membrane and scavenge hydroxyl radicals and several studies have indicated such protection against I/R in skin flaps $[\mathbf{1 2 , 1 8 ]}$.

Different studies have investigated the role of heparin in the prevention of I/R in muscle flaps [19-20] and other tissues [21,22]. These studies offer strong evidence that heparin within the vasculature of ischemic tissue can extend the period of tolerance to ischemia. The rationale for using heparin to salvage ischemic flaps has been based on its antithrombotic properties. Apart from its antithrombotic effect, heparin has three important anti-inflammatory effects that can reduce the inflammatory proc- 
ess leading to reperfusion injury [23]. First, heparin binds to $\mathrm{P}$ and $\mathrm{L}$ selectin, which may reduce the passage of leukocytes from blood into tissues [24]. Second, heparin reduces the generation of reactive oxygen species from leukocytes [25]. Finally, heparin inhibits the activation of the proinflammatory transcription factor, the nuclear factor kappa $\mathrm{B}$, thereby disrupting the inflammatory cascade [26].

Intercellular adhesions molecules (ICAM) are responsible for leukocyte-endothelial interaction which ultimately leads to ischemia reperfusion (I/R) injury [27]. The expression of endothelial Eand P-selectins and leukocyte L-selectins initiates rolling of leukocytes into endothelium. The beta2 integrins (CD18) of leukocytes trigger the release of antigen 1 of neutrophil which transforms the rolling of leukocytes into firm adhesion [29]. Neutrophil-endothelial adhesion and consequent arteriolar vasoconstriction eventually leads to noreflow condition of I/R injury [30]. Blockage of this pathway may inhibit the leukocyte-endothelial adhesion and ameliorate the reperfusion injury. Monoclonal antibodies to intercellular adhesion molecules (ICAM-1) have been used in many trials to reduce ischemia-reperfusion injury $[\mathbf{1 4 , 2 8 , 2 9 ]}$.

This study was designed to investigate the effect of the three mentioned drugs in reducing the pathology of I/R injury.

\section{MATERIAL AND METHODS}

This is a double blinded experimental animal study that have been primarily approved by the Ethics Committee on Research Animal Use, Ain Shams University, Cairo, Egypt.

\section{i- Animal Model preparation:}

Forty adult Waster Albino rats of the same age (6 months), weighing between 250-300 grams, were divided into five equal groups by a "simple random sampling method". The rats were housed in separate cages and fed with standard rat chow and water. The rats were anesthetized by intramuscular ketamine hydrochloride $(65 \mathrm{mg} / \mathrm{kg})$ plus $\mathrm{xy}-$ lazine hydrochloride $(0.65 \mathrm{mg} / \mathrm{kg})$. The skin of abdomen was shaved by hair removal cream and prepared with povidone-iodine solution $5 \%$ and placed on supine position.

\section{ii- Surgical procedure:}

A “ $4 \times 6$ " $\mathrm{cm}\left(24 \mathrm{~cm}^{2}\right)$ epigastric flap was marked by using template positioned over the epigastric skin (Fig. 1). The marked skin flap was elevated deep to the panniculus carnosus on the left abdom- inal region with vascularization. The flap was subjected to 8 hours of ischemia by clamping the inferior epigastric pedicle. The flap was repositioned on its original bed and sutured by $4 / 0$ continuous monofilament silk suture sparing the caudal border where simple stitches were used to facilitate later removal of clamp. The rats were kept in cages with free access to water and food. Close to the end of the ischemia period, the rats were anesthetized again. Fifteen minutes before the release of the vascular clamp and reperfusion, the drugs were injected intravenously through the tail veins using a 30 gauge needle with syringe. The flaps in the sham group were not subjected to ischemia and did not receive any drug injection.

\section{iii- Experiment design:}

The rats were divided into 5 groups:

Group I: Sham group $(n=8)$ : The inferior epigastric flap was raised as an island flap based on the inferior epigastric vessels, then the flap was re-sutured without induction of ischemia or infusion of any drug.

Group II: Control group ( $\mathrm{n}=8)$ : 15 minutes before reperfusion, they received intravenous $10 \mathrm{ml}$ normal saline solution $0.9 \%$.

Group III: Free oxygen scavengers (Vitamin C) $(n=8): 15$ minutes before reperfusion, they received intravenous vitamin $\mathrm{C}$ (Memphis Pharma and chemical Ind. Egypt) in a dose of $2.5 \mathrm{ml} / \mathrm{kg}$ in $0.5 \mathrm{ml}$ of $0.9 \%$ normal saline solution.

Group IV: Heparin ( $\mathrm{n}=8)$ : 15 minutes before reperfusion, they received intravenous injection of a single bolus of heparin (Nile Pharmaceuticals Co., Egypt) in a dose of 150 units/kg body weight.

Group V: Monoclonal Antibody to ICAM ( $\mathrm{n}=$ 8): 15 minutes before reperfusion, they received intravenous injection of monoclonal antibody LY6G (MAB 1037-100) (Bio-Techne, Minnesota, USA) in a dose of $0.20 \mathrm{mg} / \mathrm{kg}$ in $0.5 \mathrm{ml}$ of $0.9 \%$ normal saline.

After injection of the drugs, the vascular clamps were removed allowing reperfusion of the flaps. The vascular pedicles were observed for 30 minutes for any signs of thrombosis. Animals with suggestive local signs of thrombosis were identified and excluded from the experiment. Finally, rats were decanted.

\section{iv- Evaluation:}

Gross evaluation of flaps:

After 48 hours of reperfusion, the animals were anesthetized and the percentages of flap viability 
versus areas of skin necrosis were determined by Sasaki and Pang method [30].

\section{Neutrophil count:}

Biopsies from flaps were collected after 48 hours of reperfusion and fixed in $10 \%$ buffered formaldehyde, embedded in paraffin, and cut at $6 \mu \mathrm{m}$ thickness. All microscopic sectiosn were stained with Hematoxylin and Eosin and examined immunohistochemically by LY-6G marker specific to neutrophils. Two skin specimens were taken from each flap measuring $1 \times 1 \mathrm{~cm}^{2}$, one specimen from the distal portion and the other from the central portion of the flap. Neutrophil infiltration in the skin specimens were quantitatively counted in a non-overlapping high power fields (x 400) using an image analyzer.

\section{Biochemical analysis:}

The following two enzymes were measured in tissue samples.

1- Superoxide dismutase enzyme (SOD) assay: This enzyme activity was measured by colorimetric method using commercial kit supplied by Bio-Diagnostic Company, Egypt. The assay relied on the ability of the enzyme to inhibit the phenazine methosulphate-mediated reaction of nitroblue tetrazolium dye.

2- Caspase-3 activity assay: It was detected Fluorometrically using Bivision Research Products Assay Kit (Mountain View, CA, USA). 50mg of tissue was homogenized in $2 \mathrm{x}$ reaction buffer and incubated at $37^{\circ} \mathrm{C}$ with $1 \mathrm{~mm}$ caspase- 3 substrate (DEVD-APC) for 1 hour. Substrate cleavage was measured with a spectrofluorometer at $400 \mathrm{~nm}$.


Fig. (1): Flap model preparation: (A) 4x6 cm design of epigastric flap, (B) Island flap elevation based on inferior epigastric vessels, (C) Clamping of the vascular pedicle to create ischemia for 8 hours, (D) Reposition of the flap on the bed.

\section{RESULTS}

\section{1- Gross flap viability:}

In sham group, all flaps survived completely without any noticeable areas of necrosis. Survival of all flaps of sham group proved that there were no factors in the technique rather than ischemia that could result in flap necrosis. In control group, the percentage of flap survival ranged from $2 \pm 0.7$ to $17 \pm 2.4$ percent. The mean areas of flap survival in groups III, VI, and V were $71 \pm 12.4,80 \pm 13.8$, and $84 \pm 14$ percent respectively (Fig. 2). The pattern of flap necrosis was similar in all groups in the most distal portion of flap becoming necrotic, although some variations did occur. The best results of flap survival were reported in rats received monoclonal antibody LY-6G $(p<0.05)$.
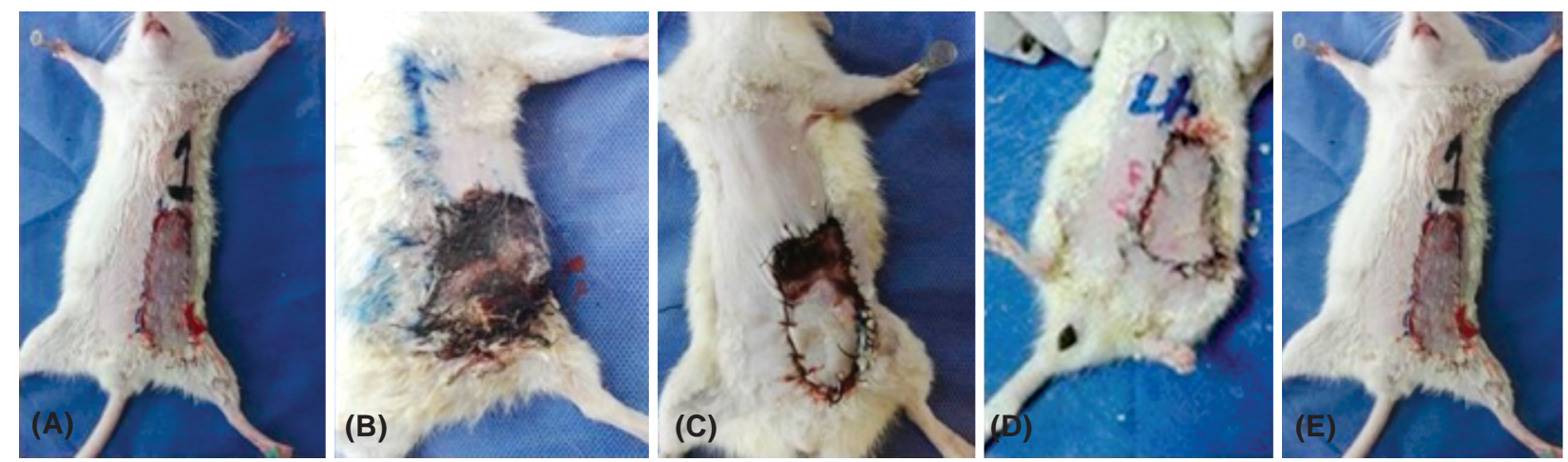

Fig. (2): Areas of flap survival versus areas of necrosis in the different group (A) Sham group (B) Control group (C) Flap received vitamin $\mathrm{C}$ (D) flap received heparin (E) Flap received monoclonal antibody. 

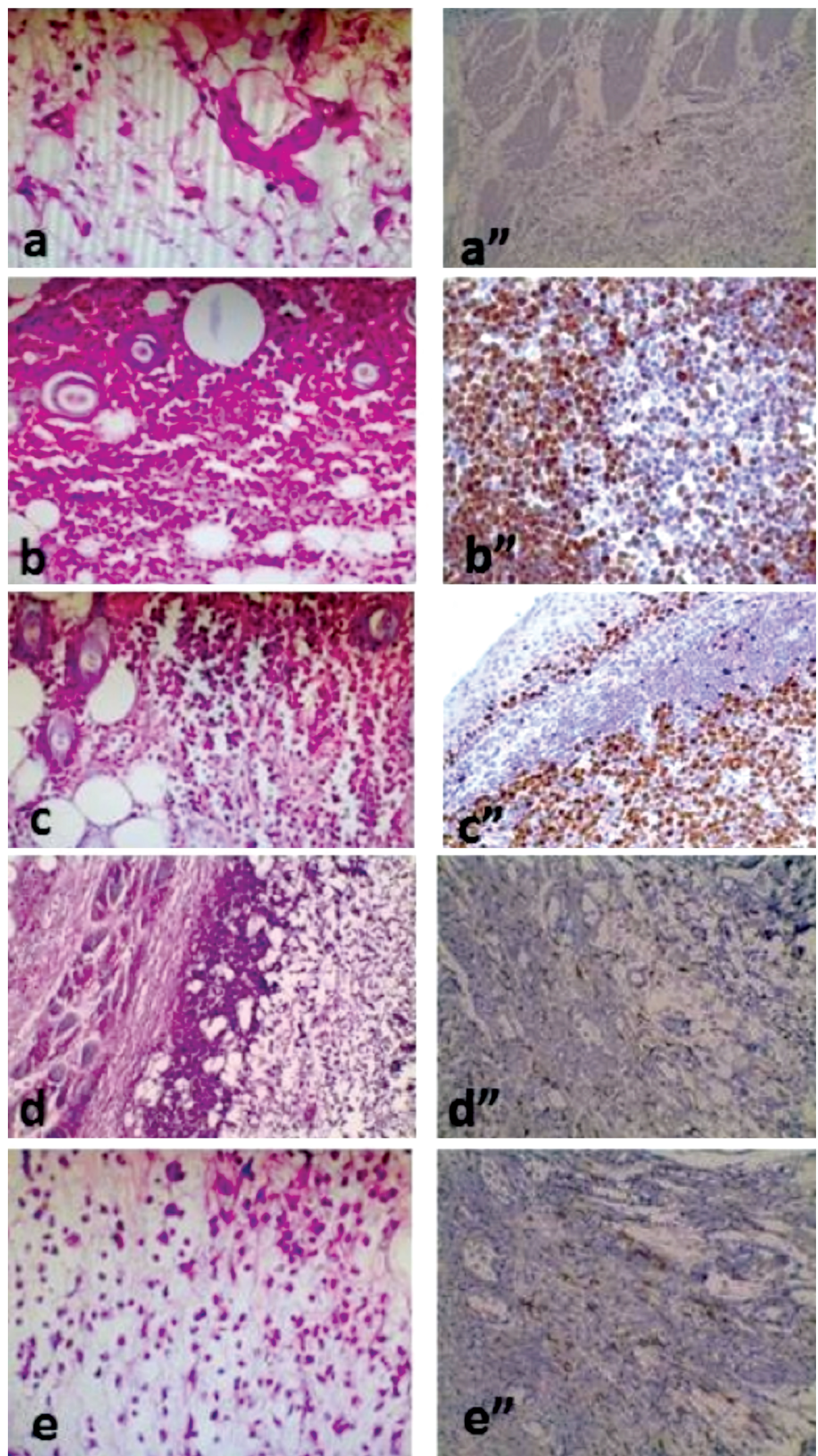

Fig. (3): Histological pictures of the neutrophil infiltrations of distal flap samples in the different groups; (a \& a") few infiltration in sham group, (b \& b") severe infiltrations in flaps of control group, (c \& $\left.c^{\prime \prime}\right)$ mild to moderate infiltrations in flaps received vitamin $c,(d \& d ")$ mild to moderate infiltrations in flaps received heparin, (e \& e") mild infiltrations in flaps received monoclonal antibody. The specimens of left column are stained by Hematoxylin and eosin (H\&E), while the specimens of right column are and immunohistochemically stained with LY-6G marker. (X400). 


\section{2- Neutrophil count:}

Distal and central neutrophil count in tissue samples of the sham group showed minimal neutrophil infiltrations (a mean of 12.71 $\pm 1.6 / \mathrm{HPF}$ distally and 9.9 $1.2 / \mathrm{HPF}$ centrally). The mean neutrophil counts per high power field in distal flap samples were $816.50 \pm 24.4,201 \pm 10.05$, $122.8 \pm 9.3$, and $25.4 \pm 3.4$ for groups II, III, VI, and $\mathrm{V}$ respectively. The mean neutrophil counts in central flap samples were 632.13 $\pm 75.8,64.49 \pm 7.7$, $46.1 \pm 5.5$, and $12.63 \pm 3.3$ for groups II, III, VI, and $\mathrm{V}$ respectively. There was a significant difference of mean values of neutrophil infiltration in the groups treated by drugs as compared to the control group $(p<0.05)$. However, the less neutrophil infiltration was reported in flaps receiving monoclonal antibody (Fig. 3).

\section{3- Biochemical enzyme assay:}

a- Superoxide dismutase enzyme (SOD): There was a significant decrement in SOD enzyme

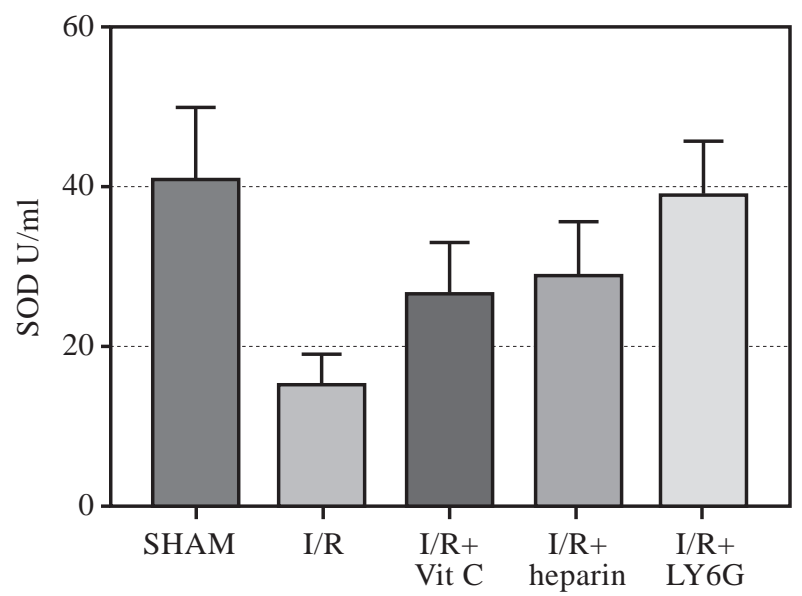

Fig. (4): A comparison between all studied groups as regards the enzymatic antioxidant biomarker, SOD Enzyme activity $(\mathrm{U} / \mathrm{ml})$, using one way ANOVA test, there were statistically significant differences among all the studied groups $(\mathrm{F}=19.76, p<0.001)$. This ANOVA test was followed by Tukey`s test to determine inter-groups variations in which SOD Enzyme activity $(\mathrm{U} / \mathrm{ml})$ were significantly decreased in (I/R + saline), (I/R + Vit.C) and (I/R + Heparin) groups when compared to the SHAM group $(p<0.001)$. But, there was a non-significant decrease in its level in the $(\mathrm{I} / \mathrm{R}+\mathrm{LY} 6 \mathrm{G})$ group when it compared to SHAM group $(p>0.05)$.

\section{DISCUSSION}

Zaccaria et al., in 1994 [12] used Vitamin C infusion to epigastric skin flaps of rats subjected to 6 hours of ischemia, and they reported higher percentages of flap survival than did the control flaps. Later on, Georgopoulos et al., in 2012 [31] reported that Vitamin $\mathrm{C}$ could reduce skin flap activity in control group when compared to the sham group. On the other hand, there was a significant increment of its activity in ischemic flaps pretreated with Vitamin $\mathrm{C}$, heparin and LY-6G (Fig. 4).

b- Caspase-3 assay: Caspase-3 activity was significantly increased in I/R groups when compared to the sham group. But it was significantly decreased in the $I / R$ rats pretreated with vit $C$, heparin and LY-6G when compared to the control group (Fig. 5).

\section{Statistics:}

The data is expressed as mean \pm SD. MannWhitney statistical analysis was used to evaluate survival difference between control and treatment groups. $p$-value $<0.05$ was considered statistically significant. ANOVA test was followed by Tukey's test to determine inter-groups variations.

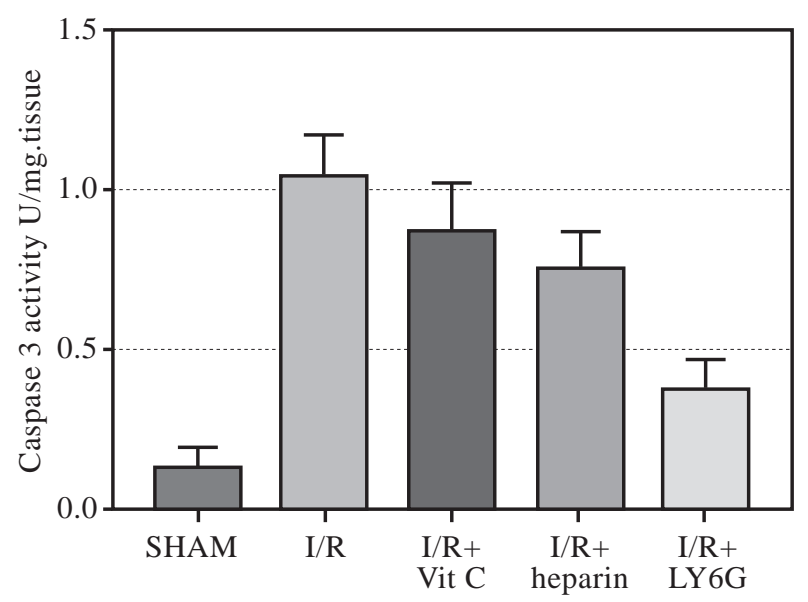

Fig. (5): A comparison between the five studied groups as regards the apoptotic marker, caspase 3 activity (U/mg. tissue), using one way ANOVA test, there were statistically significant differences between values of caspase 3 activity (U/mg. tissue) among all studied groups $(\mathrm{F}=99.04, p<0.001)$. This ANOVA test was followed by Tukey's test to determine inter-groups variations in which caspase 3 activity (U/mg. tissue) in the four I/R groups were significantly higher than SHAM group $(p<0.001)$. Moreover, there was a significant decrease in its activity in the (I/R + LY6G) group when it compared to the other three I/R groups, with no significant difference between (I/R + Vit.C) and (I/R + Heparin) $(p>0.05)$.

necrosis. In the present study, Pre-perfusion of ischemic flaps by Vitamin $\mathrm{C}$ could reduce the areas of necrosis in comparison to the massive necrosis reported at flaps treated by saline. This gross picture was supported by the neutrophil count in tissue biopsies which showed marked reduction compared to control group. 
Heparin is known to inhibit the complement cascade at multiple sites in both the classical and alternative pathways [32]. In addition, heparin is reported to inhibit neutrophil adhesion to endothelial cells in vitro, and reduce neutrophil superoxide generation, phagocytosis, and chemotaxis. It may be one or a combination of these properties of glycosaminoglycans that account for reducing the extent of tissue damage associated with I/R [33,34]. Our results provided further support for the role of heparin in reducing I/R as the percentage of flaps viability ranged from $75 \%$ to $83 \%$ with a mean of $80 \%$ with a significant reduction in neutrophil infiltrations. Hobson and his colleagues in 1989 [20] found that heparin could minimize skeletal muscle necrosis associated with I/R injury with less neutrophil infiltration. Hirigoyen et al., in 1995 [35] studied the effect of systemic heparin infusion in reducing the $\mathrm{I} / \mathrm{R}$ injury in inferior epigastric flaps of rats. Their results showed a significant increase in flap survival. Li et al., in 1995 [13] reported that heparin offers protection from $\mathrm{I} / \mathrm{R}$ when it can be introduced into the vascular network either prior to or during the ischemia period.

Several studies have shown that cell adhesion molecules on the surface polymorphonuclear neutrophils interact with those on the surface of vascular endothelium, resulting in increased vascular permeability leading to tissue edema [36,37]. One molecule implicated in leukocyte-mediated reperfusion injury is intercellular adhesion molecule 1 (ICAM 1) $[\mathbf{2 7 , 2 8 , 3 8 ] . ~ I s c h e m i a ~ r e s u l t s ~ i n ~ i n c r e a s e d ~}$ level of proinflammatory mediators and increase ICAM 1 expression on endothelial cell which ultimately promotes PMN-endothelial adhesion [39]. Some researches on post-ischemic muscle and kidney have indicated that blockade of neutrophil adhesion molecule provides some therapeutic benefits $[\mathbf{4 0 , 4 1 ]}$. The present study hypothesized that the blockade of leukocyte-endothelial adhesion by a monoclonal antibody to ICAM-1 may prevent or reduce I/R injury in skin flap model. Evaluation of flaps treated by monoclonal antibody (LY-6G) after 48 hours of reperfusion revealed a significant survival of flaps (mean 84\%). The result was highly significant when compared with those of control group treated with saline ( $2 \%$ to $17 \%$ with a mean of $9 \%$ ) and even higher than the other flaps treated by vitamin $\mathrm{C}$ and heparin. In the study conducted by Tosa et al., 1998 [14], skin flaps were subjected to 9 hours of ischemia and treated with monoclonal antibody to ICAM-1. The average viable area of flaps was $90.6 \pm 12.8$ percent compared with those of control animals receiving saline which had an average of $18.3 \pm 19.6$ percent. Demirseren et al.,
2007 [42] have reported that blocking the action of ICAM-1 in rat epigastric flaps by administering monoclonal antibody significantly attenuated ischemic injury. Pan and his colleagues in 2008 [43] studied the effect of monoclonal antibody to $\mathrm{P}$-selectin on the I/R injury of a skin flap model in rats. They reported a higher survival compared with those of control flaps received saline.

Histological examination of biopsies harvested from flaps that have been subjected to infusion of monoclonal antibody showed a marked reduction in neutrophil infiltration as compared with control and sham groups. Even the count of neutrophil infiltration was nearly close to those of the sham group (12.71/HPF distally and 9.9/HPF centrally) and much less than those of the control group $(p>001)$. These results have come in agreement with the results of the previous studies $[\mathbf{1 4 , 4 2 , 4 3 ]}$.

Superoxide dismutase (SOD) is considered as one of the most valuable enzymatic antioxidant defense systems, which plays a key antioxidant role in living cells via protecting against superoxide free radicals toxicity [44]. So, it acts as a free radicals scavenger, guarding tissues against I/R injury. It degrades superoxide $\left(\mathrm{O}^{2-}\right)$ into ordinary molecular oxygen [45]. In the present study, SOD enzyme activity was measured as an indicator of the tissue antioxidant state during I/R. The results showed a significant SOD enzyme activity decrement in the I/R groups when compared to the sham group. On the other hand, there was a significant increment of its activity in I/R rats pretreated with drugs relative to control group. The results of the current study confirmed that post-ischemic treatment of skin flaps by Vitamin C, Heparin, or monoclonal antibody to intercellular molecule (LY-6G) maintained the level of superoxide dismutase which in turn has significant protective effect against I/R injury [46]. Caspase-3 enzyme activity showed significant increase in I/R groups when compared to the sham group. But it was significantly decreased in I/R groups pretreated with vitamin $C$, heparin and LY-6G when compared to I/R control group.

In conclusion, the three investigated drugs could reduce the deleterious effect of I/R injury on skin flaps. The authors would move one step forward in the next research investigating the three drugs on eliminating I/R injury in free skin flaps of humans.

\section{REFERENCES}

1- Ames A. 3rd, Wright R.L., Kowada M., Thurston J.M. and Majno G.: Cerebral ischemia. II. The no-reflow phenomenon. Am. J. Pathol., 52 (2): 437-453, 1968. 
2- May J.W. Jr., Chait L.A., O'Brien B.M. and Hurley J.V.: The no-reflow phenomenon in experimental free flaps. Plast. Reconstr. Surg., 61 (2): 256-67, 1978.

3- Kroll S.S., Schusterman M.A., Reece G.P., Miller M.J., Evans G.R., Robb G.L. and Baldwin B.J.: Choice of flap and incidence of free flap success. Plast. Reconstr. Surg., 98 (3): 459-63, 1996.

4- Bui D.T., Cordeiro P.G., Hu Q.-Y., Disa J.J., Pusic A. and Mehrara B.J.: Free flap reexploration: Indications, treatment, and outcomes in 1193 free flaps. Plast. Reconstr. Surg., 119: 2092, 2007.

5- Davis Sears E. and Chung K.C.: Replantation of finger avulsion injuries: A systematic review of survival and functional outcomes. J. Hand Surg. Am., 36: 686-694, 2011.

6- Suominen S. and Asko-Seljavaara S.: Free flap failures. Microsurgery, 16: 396, 1995.

7- Schmidt Y., Bannasch H. and Eisenhardt S.U.: Ischemiareperfusion injury leads to significant tissue damage in free flap surgery. Plast. Reconstr. Surg., 129 (1): 174e$175 \mathrm{e}, 2012$.

8- Kerrigan C.L. and Daniel R.K.: Pharmacologic treatment of the failing skin flap. Plast. Reconstr. Surg. Nov., 70 (5): 541-9, 1982

9- Wray R.C. Jr. and Young V.L.: Drug treatment and flap survival. Plast. Reconstr. Surg.,73 (6): 939-42, 1984.

10- Pang C.Y., Forrest C.R. and Mounsey R.: Pharmacologic intervention in ischemia-induced reperfusion injury in the skeletal muscle. Microsurgery, 14 (3): 176-82, 1993.

11- Knight K.R.: Review of postoperative pharmacological infusions in ischemic skin flaps. Microsurgery, 15: 675684, 1994.

12- Zaccaria A., Weinzweig N., Yoshitake M., et al.: Vitamin $\mathrm{C}$ reduces ischemia-reperfusion injury in a rat epigastric island skin flap model. Ann. Plast. Surg., 33: 620-623, 1994.

13- Li X., Cooley B.C., Fowler J.D. and Gould J.S.: Intravascular heparin protects muscle flaps from ischemia / reperfusion injury. Microsurgery, 16 (2): 90-93, 1995.

14- Tosa Y., Lee W.P., Kollias N., Randolph M.A. and May J.W.: Monoclonal antibody to intercellular adhesion molecule 1 protects skin flaps against ischemia-reperfusion injury: An experimental study in rats. Plast. Reconstr. Surg., 10: 1586-94, 1998.

15- Cahoon N.J., Naparus A., Ashrafpour H., Hofer S.O., Huang N., Lipa J.E., Forrest C.R. and Pang C.Y.: Pharmacologic prophylactic treatment for perioperative protection of skeletal muscle from ischemia-reperfusion injury in reconstructive surgery. Plast. Reconstr. Surg., 131 (3): 473-85, 2013

16- Feller A.M., Roth A.C., Russell R.C., Eagleton B., Suchy H. and Debs N.: Experimental evaluation of oxygen free radical scavengers in the prevention of reperfusion injury to skeletal muscle. Ann. Plast. Surg., 22: 321-331, 1989.

17- Van den Heuvel M.G., Bast A., Haenen G.R., Ambergen A.W., Mermans J.F. and van der Hulst R.R.: The role of antioxidants in ischemia-reperfusion in a human DIEP flap model. J. Plast. Reconstr. Aesthet. Surg., 65 (12): 1706-11, 2012.
18- Yin Z., Ren H., Liu L., Chen W., Gan C., Jiao H. and Fan J.: Thioredoxin Protects Skin Flaps from IschemiaReperfusion Injury: A Novel Prognostic and Therapeutic Target. Plast. Reconstr. Surg., 137 (2): 511-21, 2016.

19- Wright J.G., Kerr J.C., Valeri C.R. and Hobson R.W. $2^{\text {nd: }}$ Heparin decreases ischemia-reperfusion injury in isolated canine gracilis model. Arch. Surg., 123 (4): 470-2, 1988.

20- Hobson R.W. 2nd, Neville R., Watanabe B., Canady J., Wright J.G. and Belkin M.: Role of heparin in reducing skeletal muscle infarction in ischemia-reperfusion. Microcirc Endothelium Lymphatics, 5 (3-5): 259-76, 1989.

21- Gedik H.S., Korkmaz K., Erdem H., Karakilic E., Lafci G. and Ankarali H.: Protective effect of heparin in the end organ ischemia/reperfusion injury of the lungs and heart. J. Cardiothoracic. Surg., 15 (7): 123, 2012.

22- Yener A.Ü., Çiçek M.C., Genç S.B., Özkan T., Doğan E., Bilgin B.C., Akın T., Erdem H. and Ankarali H.: Protective role of heparin in the injury of the liver and kidney on the experimental model of ischemia/reperfusion. J. Cardiothorac. Surg., 17 (9): 35, 2014.

23- Mousavi S., Moradi M., Khorshidahmad T. and Motamedi M.: Anti-Inflammatory Effects of Heparin and Its Derivatives: A Systematic Review. Adv. Pharmacol. Sci., 2015: 507151, 2015.

24- Lever R., Hoult J.R. and Page C.P.: The effects of heparin and related molecules upon the adhesion of human polymorphonuclear leucocytes to vascular endothelium in vitro. Br. J. Pharmacol., 129: 533-40, 2000.

25- Dandona P., Qutob T., Hamouda W., Bakri F., Aljada A. and Kumbkarni Y.: Heparin inhibits reactive oxygen species generation by polymorphonuclear and mononuclear leucocytes. Thromb. Res., 15; 96 (6): 437-43, 1999.

26- Thourani V.H., Brar S.S., Kennedy T.P., Thornton L.R., Watts J.A., Ronson R.S., Zhao Z.Q., Sturrock A.L., Hoidal J.R. and Vinten-Johansen J.: Nonanticoagulant heparin inhibits NF-kappaB activation and attenuates myocardial reperfusion injury. Am. J. Physiol. Heart Circ. Physiol., 278 (6): H2084-93, 2000.

27- Cotran R.S. and Pober J.S.: Cytokine-endothelial interactions in inflammation, immunity, and vascular injury. J. Am. Soc. Nephrol., 1 (3): 225-35, 1990.

28- Zamboni W.A., Stephenson L.L., Roth A.C., Suchy H. and Russell R.C.: Ischemia-reperfusion injury in skeletal muscle: CD 18-dependent neutrophil-endothelial adhesion and arteriolar vasoconstriction. Plast. Reconstr. Surg., 99 (7): 2002-7, 1997.

29- Petrasek P.F., Liauw S., Romaschin A.D. and Walker P.M.: Salvage of postischemic skeletal muscle by monoclonal antibody blockade of neutrophil adhesion molecule CD18. J. Surg. Res., 56 (1): 5-12, 1994.

30- Sasaki G.H. and Pang C.Y.: Hemodynamics and viability of acute neurovascular island skin flaps in rats. Plast. Reconsfr. Surg., 65: 152-158, 1980.

31- Georgopoulos S., Mastorakos D., Kondi-Pafiti A., Katsenis K., Arkadopoulos N., Kannas D., Archontaki M., Vestarchis N. and Kokkalis G.: Hydroxyzine, cimetidine and vitamin $\mathrm{C}$ in reducing skin flap necrosis in ischemiareperfusion injury in rats. A comparative study. J. BUON, 17 (2): 377-82, 2012. 
32- Faham S., Hileman R.E., Fromm J.R., Linhardt R.J. and Rees D.C.: Heparin structure and interactions with basic fibroblast growth factor. Science, 271: 1116-1120, 1996.

33- Jones H., Paul W. and Page C.P.: The effects of heparin and related molecules on vascular permeability and neutrophil accumulation in rabbit skin. Br. J. Pharmacol., 135 (2): 469-79, 2002.

34- Hiebert L.M., Ping T. and Wice S.M.: Enhanced antithrombotic effects of unfractionated heparin in rats after repeated oral doses and its relationship to endothelial heparin concentration. Br. J. Pharmacol., 153 (6): 1177-1184, 2008.

35- Hirigoyen M.B., Zhang W., Gordon R.E., Prabhat A., Urken M.L. and Weinberg H.: Additional benefit of heparin in the thrombolytic salvage of ischemic skin flaps. Ann. Plast. Surg., 35 (6): 612-9, 1995.

36- Springer T.A.: Adhesion receptors of the immune system. Nature, 2; 346 (6283): 425-34, 1990.

37- Patarroyo M.: Leukocyte adhesion in host defense and tissue injury. Clin. Immunol. Immunopathol., 60 (3): 33348, 1991.

38- Hubbard A.K. and Rothlein R.: Intercellular adhesion molecule-1 (ICAM-1) expression and cell signaling cascades. Free Radic. Biol. Med., 1; 28 (9): 1379-86, 2000.

39- Winn R.K., Ramamoorthy C., Vedder N.B., Sharar S.R. and Harlan J.M.: Leukocyte-endothelial cell interactions in ischemia-reperfusion injury. Ann. N. Y. Acad. Sci., 832: 311-321, 1997.
40- Petrasek P.F., Liauw S., Romaschin A.D. and Walker P.M.: Salvage of postischemic skeletal muscle by monoclonal antibody blockade of neutrophil adhesion molecule CD18. J. Surg. Res., 56 (1): 5-12, 1994.

41- Rabb H., O'Meara Y.M., Maderna P., Coleman P. and Brady H.R.: Leukocytes, cell adhesion molecules and ischemic acute renal failure. Kidney Int., 51 (5): 1463$8,1997$.

42- DEMIRSEREN M.E., SARICI M., GOKREM S. and YENIDUNYA S.: Protective effects of monoclonal antibody to intercellular adhesion molecule-1 in venous ischemia-reperfusion injury: Experimental study in rats. J. Reconstr. Microsurg., 23 (1): 41-4, 2007.

43- Pan B.H., Tosa Y., Hosaka Y., Satoh K., Yokoyama T., SAIGA A. and Yenidunya M.O.: Effect of Monoclonal Antibody to P-Selectin on Ischemia-Reperfusion Injury in Skin Flap. Showa Univ. J. Med. Sci., 20 (1): 1-10, 2008.

44- Fukai T. and Ushio-Fukai M.: Superoxide dismutases: Role in redox signaling, vascular function, and diseases. Antioxid Redox Signal, 15; 15 (6): 1583-606, 2011.

45- Perry J.J., Shin D.S., Getzoff E.D. and Tainer J.A.: The structural biochemistry of the superoxide dismutases. Biochim. Biophys. Acta., 1804 (2): 245-62, 2010.

46- Klein M.B., Chan P.H. and Chang J.: Protective effects of superoxide dismutase against ischemia-reperfusion injury: development and application of a transgenic animal model. Plast. Reconstr. Surg., 111 (1): 251-5, 2003. 